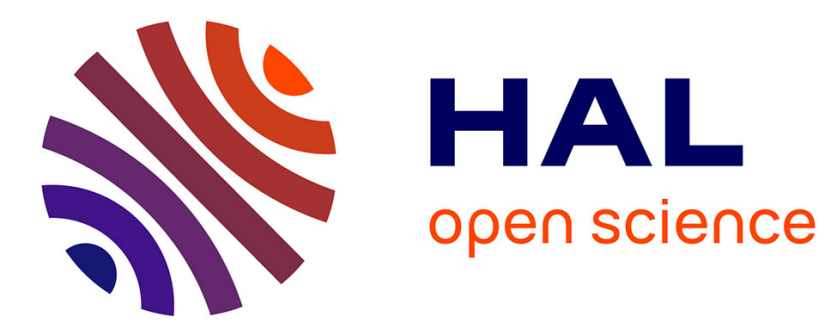

\title{
Proximal Radar Sensors for Precision Viticulture
}

Dominique Henry, Hervé Aubert, Thierry Veronese

\section{To cite this version:}

Dominique Henry, Hervé Aubert, Thierry Veronese. Proximal Radar Sensors for Precision Viticulture. IEEE Transactions on Geoscience and Remote Sensing, 2019, 57 (7), pp.4624-4635. 10.1109/TGRS.2019.2891886 . hal-02007012

\section{HAL Id: hal-02007012 https://hal.laas.fr/hal-02007012}

Submitted on 5 Feb 2019

HAL is a multi-disciplinary open access archive for the deposit and dissemination of scientific research documents, whether they are published or not. The documents may come from teaching and research institutions in France or abroad, or from public or private research centers.
L'archive ouverte pluridisciplinaire HAL, est destinée au dépôt et à la diffusion de documents scientifiques de niveau recherche, publiés ou non, émanant des établissements d'enseignement et de recherche français ou étrangers, des laboratoires publics ou privés. 


\title{
Proximal Radar Sensors for Precision Viticulture
}

\author{
Dominique Henry, Hervé Aubert, and Thierry Véronèse
}

\begin{abstract}
In this paper, we report the accurate estimation of vine grape yield from a three-dimensional radar imagery technique. Three ground-based frequency-modulated continuous-wave radars operating respectively at $24 \mathrm{GHz}, 77 \mathrm{GHz}$ and $122 \mathrm{GHz}$ are used for the contact-less estimation of grape mass in vineyards. 3D radar images are built from the beam-scanning of the vine plants and allow estimating the mass of grapes from the computation of appropriate statistical estimators. These estimators are derived from the measured polarization and magnitude of radar echoes. It is shown that the estimation of grape mass from the proposed ground-based radar imagery technique at millimeter-wave frequency range may be accurate within 1 per cent.

Index Terms — Precision viticulture, Proximal sensing, Radar imagery
\end{abstract}

\section{INTRODUCTION}

T T has been 20 years now that the concept of precision viticulture (PV) was introduced by Bramley et al. [1]. PV was proposed

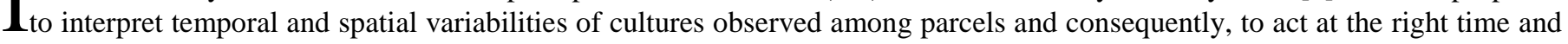
the right place. The technologies associated with PV are derived from those of the so-called precision agriculture (PA) but, contrary to PA, the aim of PV does not target intensive yield. Viticulture focuses actually on viniculture which is culturally related to the terroir, where quality and authenticity of the final product are hardly compatible with mass production. In some countries, the production is subjected to regulations which limit the yield and protect the terroir (see, e.g., "Appellation d'Origine Contrôlée" (AOC) in France, or "Denominazione di Origine Controllata" (DOC) in Italy). The production limitation, expressed in hectoliter by hectare, does not take into account eventual variabilities in the vineyard parcel due to micro-climates, ground topography, soil properties and/or grapevine diseases. Winegrowers have a strong interest in predicting and controlling the yield of their vineyard. Moreover, the estimation of grape yield before the harvest and as soon as possible, allows the early winegrowers intervention for removing part of grapevine and consequently, balancing the concentration of sugar, phenolic compounds and the titratable acid. This crucial intervention allows improving the quality of the final product. The early estimation of the yield brings other qualitative and economic impacts, such as, optimizing human resources and equipment during the harvest and, being fairly compensated by insurances in case of severe weather conditions that may damage vine stocks.

Usually, estimating the grape yield is based on the use of remote sensors embedded in satellites or aircrafts and/or on so-called proximal sensors in ground-based systems [2]. However, this estimation in the framework of PV is still very challenging. Most of remote estimations uses ground-based optical or multispectral proximal sensors. The first optical detection of grapes was reported in 2006 by R. Chamelat et al. [3] from a Red Green Blue (RGB) camera, and many algorithms were developed from RGB images to detect red or white grapes [4]-[6], to count the grapes berries [7][8], or even to detect grapes at mid-stage of the fruit set [9]. These optical systems can be embedded on vehicles [10] and 3D reconstruction of grapes from images overlapping can be applied for the contact-less estimation of grapes volume [11]. Despite their detection of grapes with very high reliability [12], optical sensors do not succeed to estimate accurately the grape yield. Best reported results indicate correlation coefficients only of $79 \%$ between the grape yield and statistical estimators [9]. The main reason is that 2D or stereo images do not bring measurement data in depth of the scene. Moreover, optical sensors may fail to detect grapes that are partially or totally hidden by leaves, shoots or other grapes. Another drawback is that, due to luminosity variation of the scene, optical sensors require calibrations, which render their application not so flexible and convenient from a practical point of view.

Other techniques are based on the measurement of the Normalized Difference Vegetation Index (NDVI) from satellites [13] at large scales, such as, e.g., the scale of several parcels [14] (correlation coefficient from 66\% to 82\%) or of a country like Portugal [15] (correlation coefficient ranging from $76 \%$ to $81 \%$ ). However, NDVI provides indirect estimation of the yield without improving performances.

To overcome limitations of optical and satellite-based techniques, we propose in this paper to use ground-based frequencymodulated continuous-wave (FM-CW) microwave or millimeter-wave radars for the estimation of the grape yield. More specifically, we define appropriate statistical estimatorsof the yield from measurement data provided by microwave and millimeterwave FMCW radars. Radars aboard satellites [16][17] or aircrafts [18][19] have been already used for vineyard application (one of the most complete work using such radar in PV was reported in 2014 by Del Frate et al. [20] for the vigor measurement and heterogeneity mapping of vineyards). However, from the best authors' knowledge, the use of ground-based radars as proximal sensors for the contact-less estimation of grape yield in vineyards is innovative. This technique was actually patented by the authors in 2016 [21]. In comparison with airborne radar systems, the influence of the soil and the canopy backscattering is strongly reduced. 
Three-dimensional (3D) radar images are built here from the beam-scanning of the scene and allow estimating the mass of grapes from the computation of appropriate statistical estimators. These estimators are defined from the measured polarization and magnitude of radar echoes. The proposed approach allows detecting most of grapes in the scene of interest, even if the grapes are partially or totally hidden by leaves, shoots or other grapes. As microwave or millimeter-wave electromagnetic field are used, the luminosity of the scene and the color of grapes have no impact on the estimation accuracy of the grape yield.

The paper is organized as follows. Section II presents the method with the detailed description of the vineyard site, and the technique from which 3D radar images are built from the beam-scanning of the scene. For performance comparison purposes, three FM-CW radars operating at different frequencies $(24 \mathrm{GHz}, 77 \mathrm{GHz}$ and $122 \mathrm{GHz}$ ) will be successively used for generating the 3D radar images. The choice of these three operating frequencies is motivated by the growing development of standalone FM-CW radars working at ISM or automotive frequency bands.

Section II will also be devoted to the description of the so-called self-adaptive algorithm for computing contours in 3D radar images. Section III details results of the yield estimation based on polarimetric analysis at $24 \mathrm{GHz}$ and on radar echo magnitude at the three operating frequencies. In Section IV, discussion and interpretation of the obtained results are finally reported.

\section{MATERIAL AND METHODS}

\section{A. Description of the vineyard}

The vineyard is located near Gaillac in the South-West of France, and radar measurements are performed within a parcel which alternates vine rows of different grape varieties. Rows are spaced $2.2 \mathrm{~m}$ apart and the field presents no significant slope. Vine plants are separated by a trunk-to-trunk distance of $1 \mathrm{~m}$. Attention is first paid to avoid experiment during rainy days, but cloudy, sunny, windy or/and moisty atmospheres have been found acceptable weather conditions for radar measurement. Five varieties of red grapes are studied to analyze the performances of the proposed grape mass estimation technique: Mourvèdre (MO), Gamay (GA), Merlot (ME), Grenache (GR) and Alicante-Bouschet (AB).

Nowadays, the yield of vineyard (from the end of August to mid of September) is in practice determined from the volume or mass measurement of grapes in vine plants. A scale is used here for this measurement with a precision of $\pm 1 \mathrm{~g}$, and is referred as the "ground-truth" of the yield estimation. Illustrative data on the harvested masses and pictures of grapes at maturation are reported in Figure 1. Table I summarizes the key characteristics of each variety of vine grapes as well as the dates of ground-truth of the yield estimation. The large variation of the mass distribution for different varieties can be observed from these measurement results. With the average mass of $170 \mathrm{~g}$, MO has the heaviest grapes while GA is characterized by more homogeneous but lighter mass of grapes, with the average mass of $63 \mathrm{~g}$ and the standard deviation of $26 \mathrm{~g}$. This heterogeneity between varieties will be used as an argument of flexibility for the grape yield estimation technique reported in this paper. Masses below 20g are viewed as residual berries that derived from main grapes, but they are taken into account in the estimation of the vine grape yield.
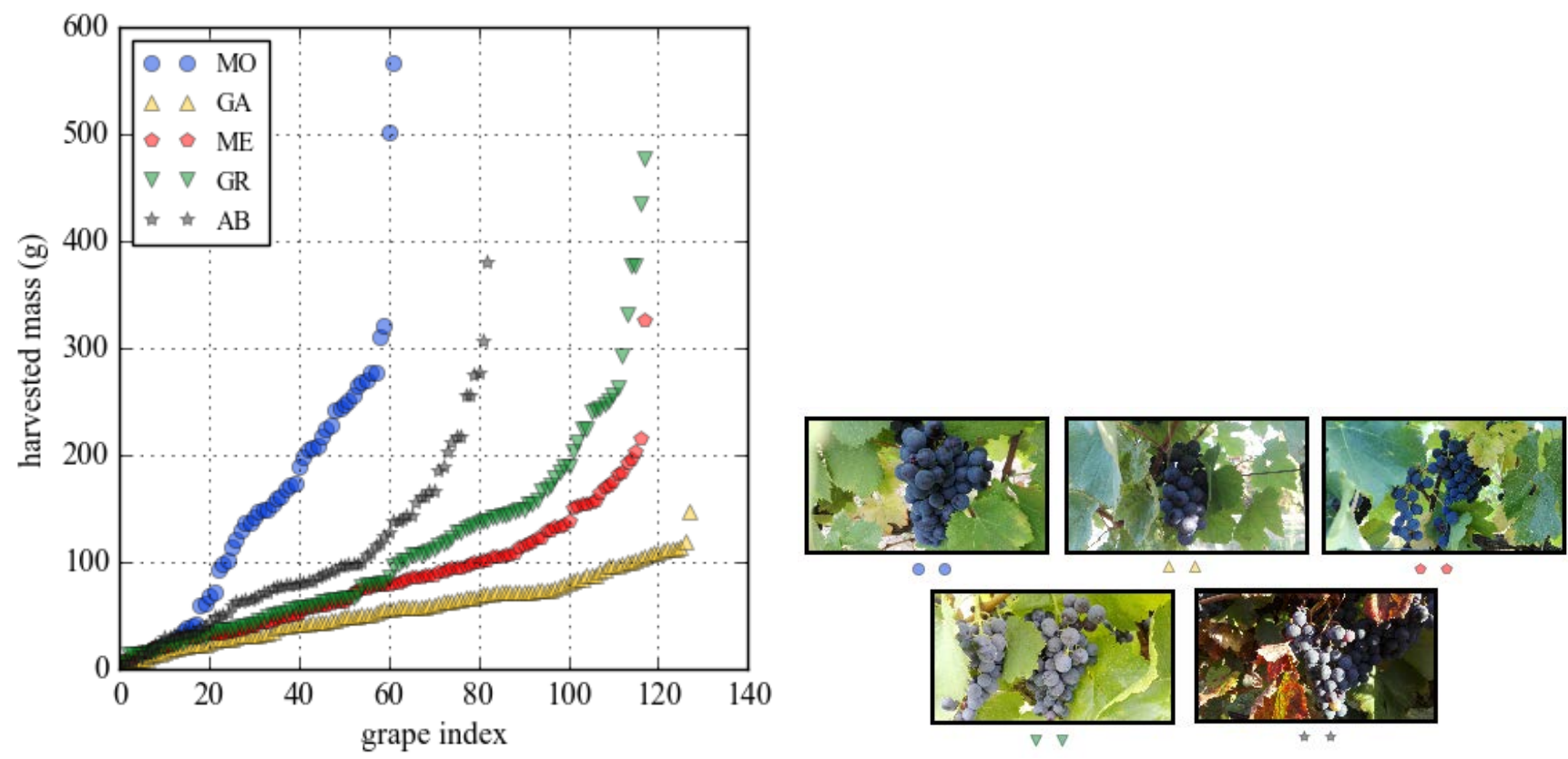

Fig. 1. Masses of harvested grapes at maturation for five consecutive vine plants and for the five different varieties. Photographs of grapes at maturation are given for the following varieties: Mourvèdre (blue circles), Gamay (yellow up-triangles), Merlot (red pentagons), Grenache (green down-triangles) and Alicante-Bouschet (black stars). 
TABLE I

MASS OF 5 VINE GRAPE VARIETIES OF INTEREST

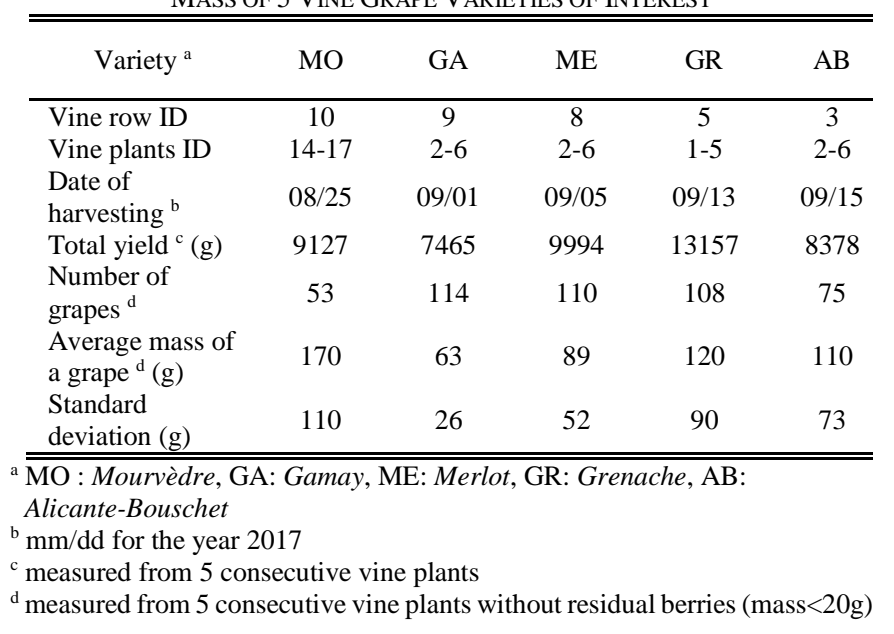

\section{B. Experimental setup}

FM-CW radars (see, e.g., [22] for the detailed description of operating principle) as proximal sensors for the estimation of the grape yield are used here. Unlike pulse-Doppler radars, FM-CW technology offers a detection of targets at a short range with lowcost devices $(<\$ 1000)$ and low output powers $(\leq 100 \mathrm{~mW})$. The use of high operating (or carrier) frequencies instead of low frequencies for our proximal radar sensors can be justified as follows:

$i$. as the wavelength at high frequencies $(>15 \mathrm{GHz})$ is smaller than the berry diameter (around $2 \mathrm{~cm}$ ), the electromagnetic interaction with grapes is stronger;

ii. as the radar modulation bandwidth $B$ can eventually reach $10 \%$ of the operating frequency, larger bandwidth -and as a result, higher depth resolution- can be achieved at higher frequencies.

The three following commercial radars have then been selected for the experiment: (a) the $D K$-sR-1030e radar operating at $24 \mathrm{GHz}$ from IMST GmbH [23], (b) the RBK_8 radar operating at 77GHz from INRAS GmbH [24], and (c) the EasyRadar operating at $122 \mathrm{GHz}$ from Silicon Radar GmbH [25]. Technical characteristics provided by manufacturers of these three radar sensors are summarized in Table II.

TABLE II

KEY CHARACTERISTICS OF THE THREE FMCW RADAR SENSORS USED IN THE EXPERIMENT

\begin{tabular}{|c|c|c|c|}
\hline Radar model & DK-sR-1030e [23] & RBK_8 [24] & EasyRadar [25] \\
\hline Manufacturer & IMST GmbH & INRAS GmbH & Silicon Radar GmbH \\
\hline Output power & $20 \mathrm{dBm}(100 \mathrm{~mW})$ & $20 \mathrm{dBm}(100 \mathrm{~mW})$ & 20 dBm (100mW) \\
\hline Carrier (operating) frequency $f_{c}$ & $23.8 \mathrm{GHz}$ & $77.5 \mathrm{GHz}$ & $125.4 \mathrm{GHz}$ \\
\hline Carrier (operating) wavelength $\lambda_{c}$ & $12.6 \mathrm{~mm}$ & $3.8 \mathrm{~mm}$ & $2.4 \mathrm{~mm}$ \\
\hline Modulation bandwidth $B$ & up to $2.0 \mathrm{GHz}$ & $3.0 \mathrm{GHz}$ & $6.8 \mathrm{GHz}$ \\
\hline Theoretical depth resolution $d$ & $7.5 \mathrm{~cm}$ & $5.0 \mathrm{~cm}$ & $2.2 \mathrm{~cm}$ \\
\hline Tx antenna(s) ${ }^{a}$ & Horn antenna with lens & $\begin{array}{c}4 \text { arrays of }(2 \times 6) \text { patches } \\
\text { antennas }\end{array}$ & Patch antenna with lens \\
\hline Tx antenna(s) gain ${ }^{a}$ & $28 \mathrm{dBi}$ & $17.2 \mathrm{dBi}$ & $0 \mathrm{dBi}$ \\
\hline Tx vertical beamwidth ${ }^{\text {a }}$ & $6^{\circ}$ & $13.2^{\circ}$ & $8^{\circ}$ \\
\hline Tx horizontal beamwidth ${ }^{\text {a }}$ & $6^{\circ}$ & $51.0^{\circ}$ & $8^{\circ}$ \\
\hline Rx antenna(s) ${ }^{b}$ & Rectangular horn & $\begin{array}{c}8 \text { arrays of }(1 \times 6) \text { patch } \\
\text { antennas }\end{array}$ & $\begin{array}{l}\text { Patch antenna with a } \\
\text { dielectric lens }\end{array}$ \\
\hline Rx antenna(s) gain ${ }^{b}$ & $20 \mathrm{dBi}$ & $15.8 \mathrm{dBi}$ & $0 \mathrm{dBi}$ \\
\hline Available polarization configuration & $\mathrm{VV}-\mathrm{VH}-\mathrm{HV}-\mathrm{HH}$ & VV $\left(\mathrm{MIMO}^{\mathrm{c}}\right)$ & VV \\
\hline Grape varieties & \multicolumn{2}{|c|}{ MO, GA, ME, GR and AB } & ME, GR and $\mathrm{AB}$ \\
\hline Elevation scanning & from $0^{\circ}$ to $30^{\circ}$ & from $-5^{\circ}$ to $25^{\circ}$ & from $0^{\circ}$ to $30^{\circ}$ \\
\hline Azimuthal scanning & from $-20^{\circ}$ to $20^{\circ}$ & Digital beamforming & from $-20^{\circ}$ to $20^{\circ}$ \\
\hline
\end{tabular}

Water is the main constituent (around $90 \%$ ) of vine grapes. At the temperature of $20^{\circ} \mathrm{C}$, the complex dielectric constant of water is of $20-30 \mathrm{j}$ at $24 \mathrm{GHz}, 10-15 \mathrm{j}$ at $77 \mathrm{GHz}$ and $8-10 \mathrm{j}$ at $122 \mathrm{GHz}$ [26]. The real relative permittivity is high and consequently, the electromagnetic reflectivity of grapes at the three selected frequencies can be advantageously used for grape detection. This detection could be achieved, at least in principle, from the illumination of the scene by a microwave or millimeter-wave electromagnetic field, and from the analysis of the resulting backscattered field or electromagnetic echoes. However, other natural 
or artificial electromagnetic reflectors (such as, e.g., trunks, leaves, shoots, irrigation hose, vine training and metallic stakes) may be present in the scene and eventually mask the vine grape echoes. The mitigation of these undesirable echoes or clutter is one of the key challenge for accurately estimating the grape yield.

For each selected FM-CW radar, the experiment is driven as follows. First, the radar is positioned in front of a vine plant row, at the distance of $1.5 \mathrm{~m}$. The transmitting (Tx) antenna of the radar is directive (with a beamwidth of few degrees) and allows transmitting so-called chirps (i.e., triangular frequency-modulated signals) in controlled directions by mean of a beam scanning. The signal backscattered by the illuminated scene is collected by the radar receiving ( $\mathrm{Rx})$ antenna. In each direction, the so-called beat frequency spectrum is derived from the Fast Fourier Transform of the mixing of transmitted and reflected signals. This spectrum provides the magnitude of the backscattered signal in the corresponding direction (and at a given polarization) as a function of the distance or range from the radar. The theoretical depth resolution $d$ is given by $c / 2 B$, where $c$ and $B$ denote respectively the speed of light in vacuum and the modulation bandwidth [22]. The angular scanning of the Tx-antenna results into a 3D electromagnetic backscattering map of the vine plant. The radar beam scanning is performed mechanically at $24 \mathrm{GHz}$ and at $122 \mathrm{GHz}$ by using a pan-tilt. The angular scanning is performed between $0^{\circ}$ to $30^{\circ}$ in elevation (denoted by angle $\theta$ ) and between $-20^{\circ}$ to $20^{\circ}$ in azimuth (denoted by angle $\varphi$ ), with the angular step of $1^{\circ}$. The pan-tilt is synchronized with the transmitting of chirps through a Central Processing Unit (CPU). Instead of using an azimuthal beam scanning, the 77GHz RBK_8 radar performs a digital beamforming by using MIMO (Multiple Inputs Multiple Outputs) configuration, while the mechanical beam scanning is performed in elevation. Once the beam scanning of the scene is complete, the radar sensor is moved on the distance of about $1 \mathrm{~m}$ along the vine row and another beam scanning is performed. The schematic of the measurement set up and the photography of the system are shown in Figure 2.

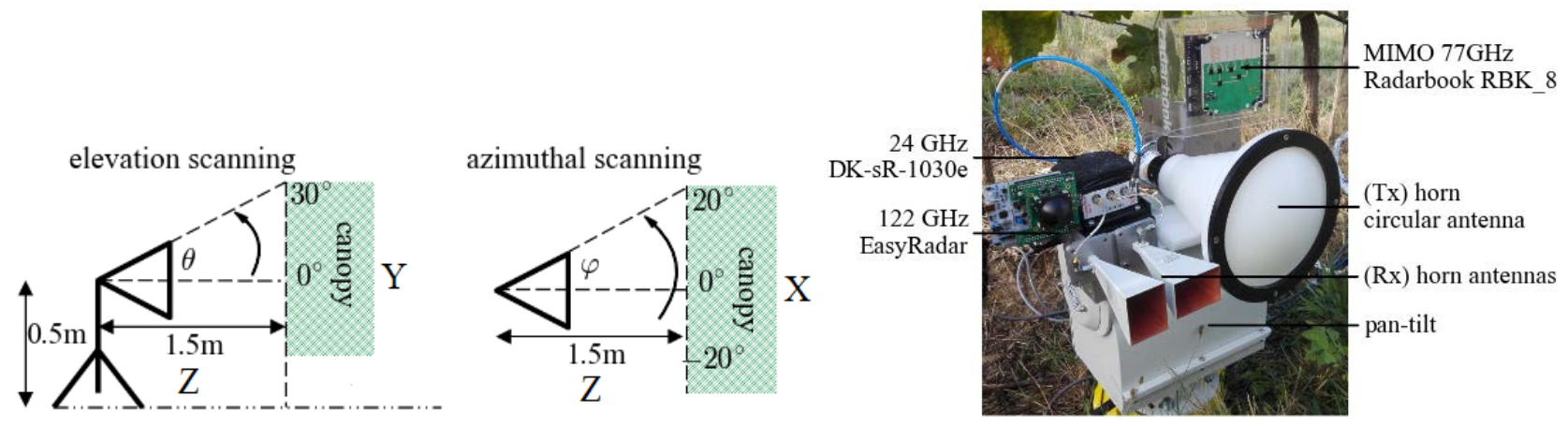

Fig. 2. (a) Measurement set up for the elevation (left) and azimuthal (right) radar beam-scannings. (b) photograph of the proximal sensor including three FM-CW radars..

\section{C. $3 D$ radar images of the vine plants}

For each vine plant, the radar beam scanning generates 3D image from which the mass of vine grape must be derived. This image is composed of 3D unit cells, called voxels. The volume of one voxel $v_{R e s}(R)$ at range $R$ from the radar is derived from a straightforward geometrical analysis and is given as follows:

$$
v_{R e s}(R)=\left(2 R^{2}+\frac{d^{2}}{6}\right) d d_{\varphi} \sin \frac{d_{\theta}}{2}
$$

where $d_{\theta}$ and $d_{\varphi}$ denote the angular resolutions in elevation and azimuth, respectively, and $d$ designates the theoretical depth resolution of the radar. The voxel volume $v_{R e s}(R)$ as well as the azimuthal/elevation coordinates are illustrated in Figure 3 . This volume at $R=2 \mathrm{~m}$ is of $91 \mathrm{~cm}^{3}$ for the $24 \mathrm{GHz} D K-s R-1030$ e radar, while it is only of $27 \mathrm{~cm}^{3}$ for the $122 \mathrm{GHz}$ EasyRadar due to the larger modulation bandwidth $B$. Moreover, the voxel volume at range $R=2 \mathrm{~m}$ of the $77 \mathrm{GHz} R B K \_8$ radar is of $85 \mathrm{~cm}^{3}$ by selecting the azimuthal resolution $d_{\varphi}$ of $1.4^{\circ}$ in the digital beamforming. 


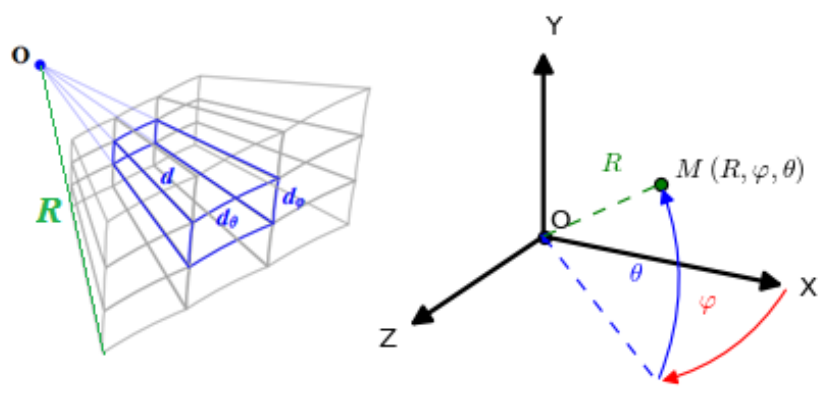

(a)

(b)

Fig. 3. (a) Representation of a voxel volume at range $R$ from the radar (located at point $\mathrm{O}$ ), and (b) azimuthal/elevation angles and Cartesian coordinates used for the beams-canning. The $\mathrm{X}, \mathrm{Y}$ and $\mathrm{Z}$ axes refer respectively to the width, height and theoretical depth of the voxel volume.

A geometrical transformation is applied to the representation of voxels in azimuthal/elevation coordinates $(R, \varphi, \theta)$ to derive this representation in Cartesian coordinates $(X, Y, Z)$. The $\mathrm{X}, \mathrm{Y}$ and $\mathrm{Z}$ axes refer respectively to the width, the height and the depth of the voxel volume.

The radar echoes are displayed by computing isosurfaces. The isosurfaces are sets of voxels inside whom the echo has the same magnitude. These surfaces are computed from the marching cubes method [27][28] and are determined for different echo levels. They are superimposed to build the 3D radar image of the scene. For illustration purpose, isosurfaces are displayed in Figure 4 (a) for the vine plant GR $n^{\circ} 3$. They are obtained from the $24 \mathrm{GHz} D K-s R-1030$ e radar (polarizations of transmitted and received electric fields are linear and vertical). In each voxel volume, the magnitude (or level) of the radar echo is displayed by using a color scale (high levels are indicated in red while low levels are in blue). The Figure 4 (b) shows the photography of the corresponding illuminated scene. The canopy is clearly apparent in the radar image but, claiming that only vine grapes generate echoes is a misinterpretation of the image that would lead to an erroneous or highly inaccurate yield estimation. As previously mentioned, radar echoes can be generated by many natural or artificial scatterers in the scene such as, e.g., trunks, leaves, shoots, irrigation hose, vine training and metallic stakes. The fine analysis of such 3D radar image must be applied in order to isolate the echoes that originate from vine grapes only.
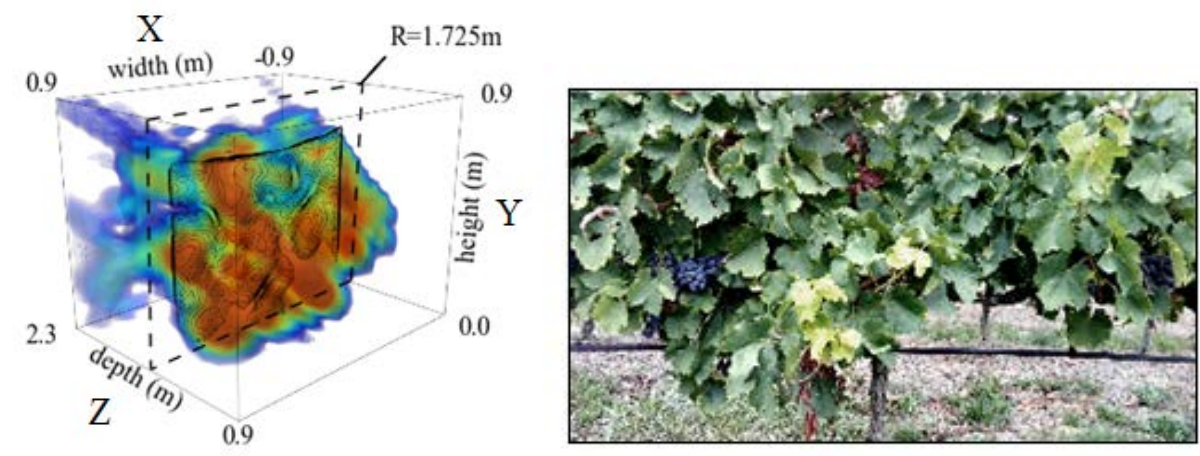

Fig. 4. (a) $3 \mathrm{D}$ radar images of the vine plant GR $\mathrm{n}^{\circ} 3$ using the $24 \mathrm{GHz}$ FM-CW radar. Echo level takes values between $-60 \mathrm{~dB}$ (blue) and $-40 \mathrm{~dB}$ (red). The transmitted and received electric fields are both vertically polarized; (b) Photograph of the vine plant GR $n^{\circ} 3$ illuminated by the radar (Note that leaves hide most of grapes).

\section{Detection of all radar echo peaks from the self-adaptive algorithm}

In order to study the spatial distribution of echo peaks in 3D radar images, the standard marching squares algorithm [27] is used here. For a given echo threshold, the algorithm generates a contour in every $(\theta, \varphi)$ plane of the 3D image. For the sake of illustration, such contours are displayed in Figure 5 (a) for the GR n ${ }^{\circ} 3$ and for different echo thresholds between -60dB (in blue) and -30dB (in red) at range $R=1.725 \mathrm{~m}$. For lower thresholds, contours delimit surface domains with many peaks while for higher thresholds, some peaks are not surrounded by contours and as a result, they are not detected. To enhance the detection of all peaks in 3D radar image, the so-called self-adaptive algorithm is proposed here for computing the contours. As illustrated in Figure 5 (b), this computation allows deriving contours that surround one echo peak only. The algorithm, described by the flowchart displayed in Figure 6, consists of two following steps: (1) The contours are first computed for different echo thresholds $t$ by using the function 
find_contours available from the scikit-image library [29]; (2) Next, the number of local maxima in the surface domain delimited by each contour is computed from the function maximum_filter from the Scipy library [30]. Until there is only one local maximum in the computed domain, other contours are generated for higher echo thresholds. As illustrated in Figure 5 (b) and as expected, this computation allows deriving contours that surround one echo peak only.
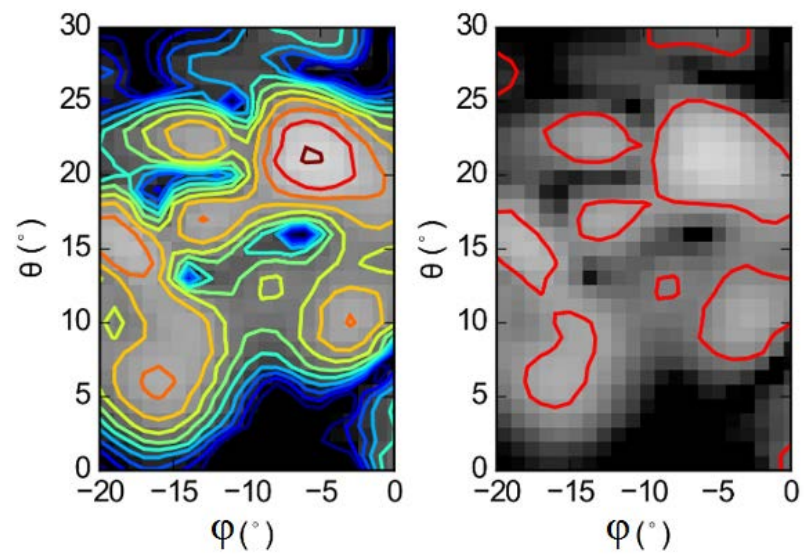

Fig. 5. (a) Contours generated at different echo thresholds from -60dB (blue) to - $30 \mathrm{~dB}$ (red) in the region of interest in the plane $(\varphi, \theta)$ at $R=1.725 \mathrm{~m}$ for the GR $n^{\circ} 3$ vine plant. This region is shown in (b) with contours (in red) computed from the proposed selfadaptive algorithm.

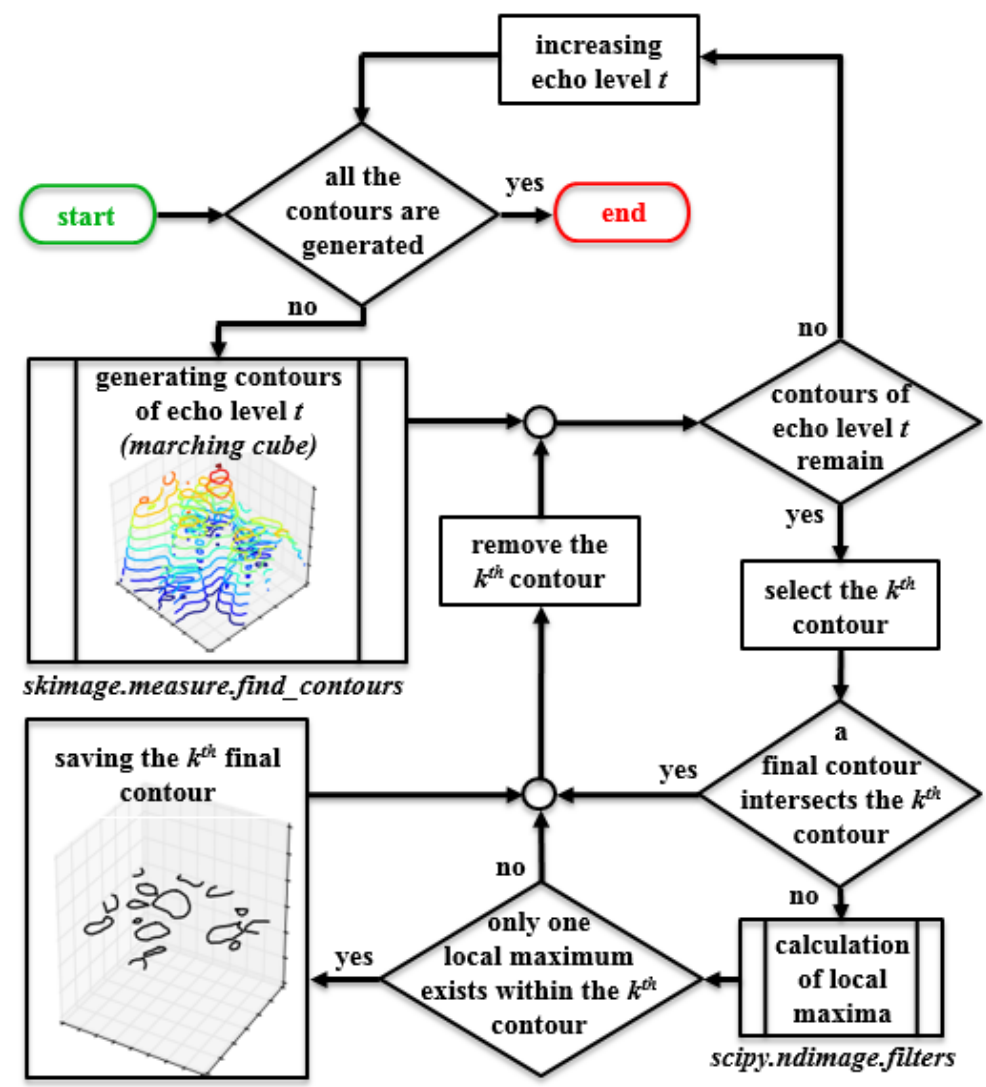

Fig. 6. Flowchart of the proposed self-adaptive algorithm for the computation of contours used to isolate all echo peaks in 3D radar images.

In the given $(\theta, \varphi)$ plane at range $R$, let $\mathcal{C}$ be the contour delimiting the surface domain $S$ that includes only one echo peak. This contour is computed from the above-described self-adaptive algorithm. Eight useful descriptors are then derived:

i. $\quad$ the surface $s(\mathcal{C})$ (in pixels ${ }^{2}$ or $\mathrm{m}^{2}$ ) of domain $S$;

ii. $\quad$ the number $p x(\mathcal{C})$ of pixels in domain $S$;

iii. the volume $\operatorname{Vol}(\mathcal{C})\left(\right.$ in voxels ${ }^{3}$ or $\mathrm{m}^{3}$ ) of the cylinder with base $S$ and height $d\left[\operatorname{Vol}(\mathcal{C})=s(\mathcal{C}) d=p x(\mathcal{C}) v_{\text {res }}(R)\right]$; 
iv. the echo threshold $t(\mathcal{C})$ (in $\mathrm{dB}$ ) used for computing the contour $\mathcal{C}$;

$v$. the coordinates $R(\mathcal{C}), \theta(\mathcal{C}), \varphi(\mathcal{C})$ of the barycenter of domain $S$;

$v i$. the echo peak $e_{\max }(\mathcal{C})$ (in $\mathrm{dB}$ ) in domain $S$;

vii the echo mean value $e_{\text {mean }}(\mathcal{C})$ (in $\mathrm{dB}$ ) in domain $S$;

viii. the standard deviation $e_{\text {std }}(\mathcal{C})$ (in $\mathrm{dB}$ ) of radar echoes within domain $S$.

As it will be shown in the next sections, these eight descriptors play a crucial role for extracting information about the electromagnetic backscattering of the scene and for estimating the grape yield from 3D radar images.

\section{Yield Estimation fROM PROXIMAl RADAR Polarimetry}

The first estimation of the grape yield is reported in this Section from a polarimetric analysis of radar echoes.

\section{A. Polarization parameter and yield estimation: definitions}

Throughout this paper, the subscript $u$ denotes the vertical $(u=V)$ or horizontal $(u=H)$ polarization of a linearly-polarized electric field. Moreover, the subscript $u v$ is called here the polarization configuration and refers to the vertical $(u=V)$ or horizontal $(u=H)$ polarization of the transmitted electric field, and the vertical $(v=V)$ or horizontal $(v=H)$ polarization of the received electric field. The estimation of grape yield from the $24 \mathrm{GHz}$ radar with vertically-polarized (transmitted and received) electric fields was recently reported by the authors in [31]. Promising results were obtained from such (non-polarimetric) analysis, but the estimation was dependent on the grape variety. For the first time, we propose in this section a variety-independent estimation of the yield.

Let $\chi_{q}^{p}$ be the polarization parameter defined as follows:

$$
\chi_{q}^{p}\left(\mathcal{C}_{k}^{p}\right)=\frac{e_{\operatorname{Max}}^{p}\left(\mathcal{C}_{k}^{p}\right)}{e_{\operatorname{Max}}^{q}\left(\mathcal{C}_{k}^{p}\right)}
$$

where $p=u v$ and $q=u$ ' $v$ ' denote two different polarization configurations, and $\mathcal{C}_{k}^{p}$ designates the $k$-th contour computed in the polarization configuration $p$ from the self-adaptive algorithm applied to the 3D radar image (see section II.D). Moreover, $e_{\text {Max }}^{p}\left(\mathcal{C}_{k}^{p}\right)$ and $e_{\operatorname{Max}}^{q}\left(\mathcal{C}_{k}^{p}\right)$ in eq.(2) are the echo peaks (in linear scale) within the surface domain delimited by the contour $\mathcal{C}_{k}^{p}$ and for the polarization configurations $p$ and $q$, respectively. As a consequence, if $\chi_{V V}^{V H}\left(\mathcal{C}_{k}^{V H}\right)$ is much greater than 1 then the surface bordered by the contour $\mathcal{C}_{k}^{V H}$ strongly depolarizes the incident vertically-polarized electric field. Moreover, if $\chi_{H V}^{V H}\left(\mathcal{C}_{k}^{V H}\right)$ is much greater than 1 then the depolarization of a vertically-polarized transmitted electric field is larger than the depolarization of a horizontallypolarized transmitted field.

Next, we conjecture that it exists a statistical estimator $E_{n}^{P o l}$ which is linearly-dependent on the grape yield of the $n$-th vine plant, which is:

$$
y_{n}=\alpha E_{n}^{P o l}+\beta
$$

where $y_{n}$ is the total grape mass of the $n$-th vine plant, and the real coefficients $\alpha$ and $\beta$ denote respectively the slope and the intercept of the linear model. The conjectured statistical estimator $E_{n}^{P o l}$ can be defined by assuming that the yield increases when the total surface of all domains delimited by the computed contours increases. Moreover, in order to reduce the impact of the clutter on the yield estimation, the $k$-th surface $s_{k}^{p}$ bordered by contour $\mathcal{C}_{k, n}^{p}$ can be weighted in the definition of $E_{n}^{P o l}$ by the polarization parameter $\chi_{q}^{p}\left(\mathcal{C}_{k, n}^{p}\right)$, as follows:

$$
E_{n}^{P o l}=\sum_{p=V V, V H, H V, H H} \sum_{q \neq p} a_{q}^{p} x_{n, q}^{p}
$$

with

$$
x_{n, q}^{p}=\frac{1}{s_{R E F}^{p}} \sum_{k=1}^{K_{n}^{p}} s_{k}^{p}\left(\mathcal{C}_{k, n}^{p}\right) \chi_{q}^{p}\left(\mathcal{C}_{k, n}^{p}\right)
$$

where $K_{n}^{p}$ is the number of computed contours for the polarization configuration $p$ and for the $n$-th vine plant, and $s_{R E F}^{p}$ designates the reference surface defined as follows. First, let $s_{t o t}^{p}$ be the sum of all surfaces that are delimited by the contours computed from the self-adaptive algorithm described in Section II.D:

$$
s_{\text {tot }}^{p}=\sum_{n=1}^{N_{0}} \sum_{k=1}^{K_{n}^{p}} s_{k}^{p}\left(\mathcal{C}_{k, n}^{p}\right)
$$

where $N_{0}$ denotes the number of vine plants used for the grape yield estimation. This surface is displayed in Figure $7($ a) for various 
polarization configurations $p$ and as a function of the deviation $\delta t$ from the initial threshold $t_{\text {init }}$ used for starting the self-adaptive algorithm.
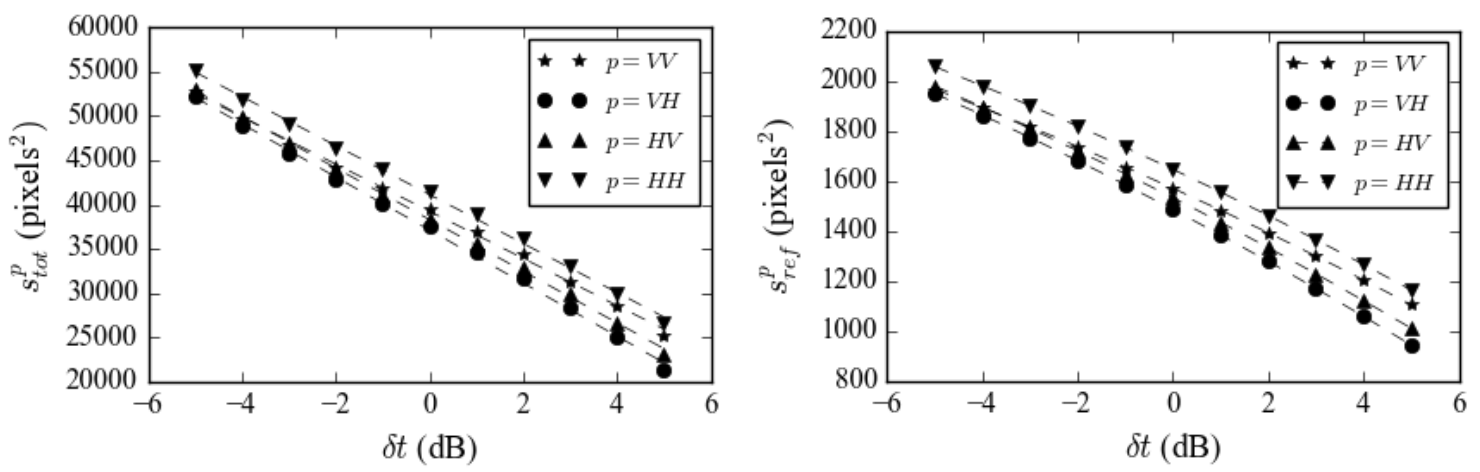

Fig. 7. (a) Sum $s_{\text {tot }}^{p}$ of all surfaces that are delimited by the contours computed from the self-adaptive algorithm described in Section II.D as a function of deviation $\delta t$ from the initial threshold $t_{\text {init }}$ and for various polarization configurations $p(=\mathrm{VV}, \mathrm{VH}$, $\mathrm{HV}$ and $\mathrm{HH}$ ). (b) Reference surface $s_{R E F}^{p}$ used for defining $E_{n}^{P o l}$ (see eq.(4)) in order to minimize the impact of $\delta t$ on the mass estimation.

As expected, $s_{\text {tot }}^{p}$ decreases as $\delta t$ increases, and it can be observed that an extremely high linearity (the coefficient of determination $R^{2}$ is of 0.99 ) of $s_{t o t}^{p}$ is obtained for all polarization configurations. As a result, $s_{t o t}^{p}$ may be modelled as follows:

$$
s_{t o t}^{p}=\alpha_{R E F}^{p} \delta t+\beta_{R E F}^{p}
$$

where $\alpha_{R E F}^{p}$ and $\beta_{R E F}^{p}$ denote respectively the slope and the intercept of the linear model in the polarization configuration $p$. In order to minimize the impact of $\delta t$ on the yield estimation, the reference surface $s_{R E F}^{p}$ is then defined as follows:

$$
s_{R E F}^{p}=\frac{\left(1+\delta_{\alpha} \delta t\right) s_{t o t}^{p}}{N_{0}}
$$

where $\delta_{\alpha}$ is derived from the following relationship:

$$
1+\delta_{\alpha} \delta t=\frac{\alpha(\delta t)}{\alpha}
$$

in which $\alpha(\delta t)$ is the slope of the linear model for the estimator $E_{n}^{P o l}$ and for the threshold deviation $\delta t$ (see eq.(3) for the definition of the slope $\alpha$ ). From eq.(7-b), $\delta_{\alpha}$ is found to be of $0.013 \mathrm{~dB}^{-1}$. The resulting reference surface is displayed in Figure 7(b) for various polarization configurations.

\section{B. Yield statistical estimator from a polarimetric analysis}

In this section, real coefficients $a_{q}^{p}$ defined in eq.(4-a) are computed. These coefficients are derived from solving the following equation:

where

$$
Y=A X
$$

with $\left\{\begin{aligned} Y & =\left[\begin{array}{llllll}y_{1} & y_{2} & \ldots & y_{n} & \ldots & y_{N}\end{array}\right]^{T} \\ A & =\left[\begin{array}{llllll}\beta & \alpha . a_{V H}^{V V} & \ldots & \alpha . a_{q}^{p} & \ldots & \alpha \cdot a_{H V}^{H H}\end{array}\right]^{T} \\ X & =\left[\begin{array}{cccccc}1 & x_{1, V H}^{V V} & \ldots & x_{1, q}^{p} & \ldots & x_{1, H}^{H H} \\ \vdots & \vdots & \ddots & \vdots & \ddots & \vdots \\ 1 & x_{n, V H}^{V V} & \ldots & x_{n, q}^{p} & \ldots & x_{n, H V}^{H H} \\ \vdots & \vdots & \ddots & \vdots & \ddots & \vdots \\ 1 & x_{N, V H}^{V V} & \ldots & x_{N, q}^{p} & \ldots & x_{N, H V}^{H H}\end{array}\right]\end{aligned}\right.$ 
In eqs.(8)-(9), the superscript $T$ denotes the transpose operator, $N$ designates the total number of measurements, $X$ is a $N \times(M+$ 1) matrix where $M$ is the total number of polarization configurations. The matrix $A$ is computed from the following equation:

$$
A=X^{\dagger} Y+\left[I-X^{\dagger} X\right] r
$$

where $X^{\dagger}$ denotes the Moore-Penrose pseudo-inverse matrix of $X, I$ is the identity matrix and $r$ designates an arbitrary vector [32]. The coefficient of determination $R^{2}$ for the linear regression model of eq.(3) tends to 1 when the term $\left[I-X^{\dagger} X\right] r$ is smaller compared with the term $X^{\dagger} Y . X^{\dagger}$ is calculated here by using the Python library (linalg.pinv function [33]) which computes the Singular Value Decomposition (SVD) method [34]. In eqs.(5)-(6) the vector $Y$ is composed of masses of grapes per vine plant, as well as the sum of masses of grapes in consecutive vine plants. Such combination is illustrated in Figure 8 for a given variety of grapevine. Grape masses $m_{1}, m_{2}, m_{3}, m_{4}$ and $m_{5}$ of five consecutive vine plants are displayed in black color. Red, blue, purple and green colors represent respectively the masses of two $\left(m_{1}+m_{2}, \ldots, m_{4}+m_{5}\right)$, three $\left(m_{1}+m_{2}+m_{3}, \ldots, m_{3}+m_{4}+m_{5}\right)$, four $\left(m_{1}+m_{2}+m_{3}+m_{4}\right.$, $\left.m_{2}+m_{3}+m_{4}+m_{5}\right)$ or five $\left(m_{1}+m_{2}+m_{3}+m_{4}+m_{5}\right)$ consecutive vine plants. These colors will be used throughout the paper for identifying mass combinations.

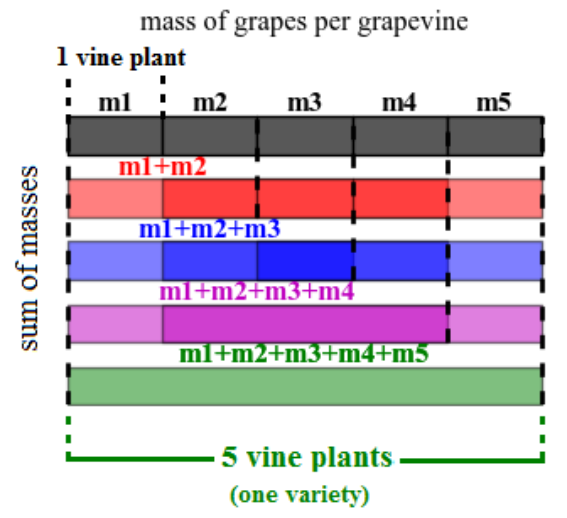

Fig. 8. Illustration of the combination of grape masses applied to a given variety of grapevine for building the vector $Y$ in eqs.(8)(9). Throughout the paper, these colors are used for indicating the corresponding mass combination.

The coefficients $a_{q}^{p}$ in eq.(6) are derived from the mass of grapes measured after the harvest for the five grapevine varieties (MO, GA, ME, GR and AB) and by using successively the different mass combinations. In Table III, the coefficients $a_{q}^{p}$ as well as ratios $\sigma / \mu$ between the standard deviation and mean value of these coefficients are reported. The ratio $\sigma / \mu$ for $a_{H H}^{V H}, a_{V V}^{H V}, a_{H H}^{H V}$ and $a_{V V}^{H H}$ exceeds $10 \%$ and, as a result, we observed that the yield is overestimated when these four coefficients are included in the computation of the vector $A$. Consequently, they are removed from further yield estimation and only the eight remaining coefficients $a_{q}^{p}$ are used for computing the vector $A$ in eq.(6).

TABLE III

COEFFICIENTS $a_{p}^{q}$ AND THEIR RELATIVE DISPERSIONS $\sigma / \mu$

\begin{tabular}{cccccc}
\hline \hline $\mathrm{N}^{*}$ & 45 & 60 & 70 & 75 & $\sigma / \mu^{* *}(\%)$ \\
\hline$a_{V H}^{V V}$ & -0.40 & -0.44 & -0.42 & -0.42 & 2.9 \\
$a_{V H}^{V V}$ & 0.37 & 0.39 & 0.37 & 0.37 & 1.4 \\
$a_{H H}^{V V}$ & -0.10 & -0.10 & -0.09 & -0.09 & 4.0 \\
$a_{V V}^{V H}$ & -0.03 & -0.03 & -0.03 & -0.03 & 6.4 \\
$a_{H V}^{V H}$ & 0.10 & 0.12 & 0.11 & 0.11 & 1.2 \\
$\boldsymbol{a}_{\boldsymbol{H H}}^{V H}$ & 0.02 & 0.02 & 0.02 & 0.01 & $\mathbf{2 2 . 3}$ \\
$\boldsymbol{a}_{\boldsymbol{V} V}^{H V}$ & 0.01 & 0.01 & 0.01 & 0.00 & $\mathbf{2 4 . 8}$ \\
$a_{V H}^{H V}$ & -0.10 & -0.10 & -0.10 & -0.10 & 5.4 \\
$\boldsymbol{a}_{\boldsymbol{H H}}^{H V}$ & 0.01 & 0.01 & 0.01 & 0.02 & $\mathbf{3 9 . 7}$ \\
$\boldsymbol{a}_{V V}^{H \boldsymbol{H}}$ & -0.01 & -0.01 & -0.01 & -0.01 & $\mathbf{1 1 . 5}$ \\
$a_{V H}^{H H}$ & 0.68 & 0.65 & 0.66 & 0.66 & 0.8 \\
$a_{H V}^{H H}$ & -0.44 & -0.42 & -0.43 & -0.44 & 1.0 \\
\hline \hline
\end{tabular}


The final yield estimation is reported in Table IV. For the five selected grapevine varieties, Figure 9(a) displays the estimated grape mass (obtained before the harvest) as a function of the harvested mass. The coefficient of determination for the linear regression model is found close to $1\left(R^{2}=0.96\right)$ and enlightens the high linearity of the estimator $E_{n}^{P o l}$.

TABLE IV

YieLd ESTIMATION BASED ON THE PROPOSED POLARIMETRIC ANALYSIS

\begin{tabular}{cc|cc}
\hline \hline \multicolumn{2}{c}{ Characteristics } & \multicolumn{2}{c}{ Model parameters } \\
\hline Total harvested mass $(\mathrm{kg})$ & 48.1 & $\alpha(\mathrm{g})$ & $3.2 \mathrm{E}-5$ \\
Total estimated mass $(\mathrm{kg})$ & 48.6 & $\beta(\mathrm{g})$ & $3.1 \mathrm{E}-3$ \\
$R^{2}$ & 0.96 & $a_{V H}^{V V}$ & -0.40 \\
error $\varepsilon_{\text {lin }}(\mathrm{kg})^{\mathrm{a}}$ & 0.50 & $a_{V H}^{V V}$ & -0.09 \\
$\varepsilon_{\mathrm{m}}(\mathrm{m}>3 \mathrm{~kg})^{\mathrm{b}}$ & $15.0 \%$ & $a_{H V}^{V V}$ & 0.03 \\
$\varepsilon_{\mathrm{m}}(\mathrm{m}>4 \mathrm{~kg})^{\mathrm{b}}$ & $7.0 \%$ & $a_{V V}^{V H}$ & -0.04 \\
$\varepsilon_{\mathrm{m}}(\mathrm{m}>5 \mathrm{~kg})^{\mathrm{b}}$ & $5.5 \%$ & $a_{H V}^{V H}$ & 0.23 \\
$\varepsilon_{\mathrm{m}}(\mathrm{m}>6 \mathrm{~kg})^{\mathrm{b}}$ & $4.8 \%$ & $a_{V H}^{H V}$ & -0.06 \\
$\varepsilon_{\mathrm{m}}(\mathrm{m}>7 \mathrm{~kg})^{\mathrm{b}}$ & $7.2 \%$ & $a_{V H}^{H H}$ & 0.76 \\
$\varepsilon_{\mathrm{m}}$ total & $1.1 \%$ & $a_{H V}^{H H}$ & -0.43 \\
\hline \hline
\end{tabular}

a error of the linear model [see definition in eq. (11)]

${ }^{\mathrm{b}}$ mean error of the yield estimation for harvested mass higher than the given mass $m$ [see eq. (12-a)]

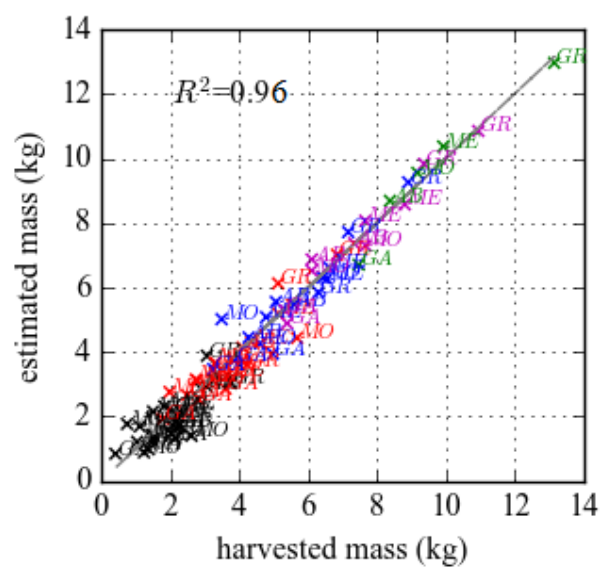

(a)

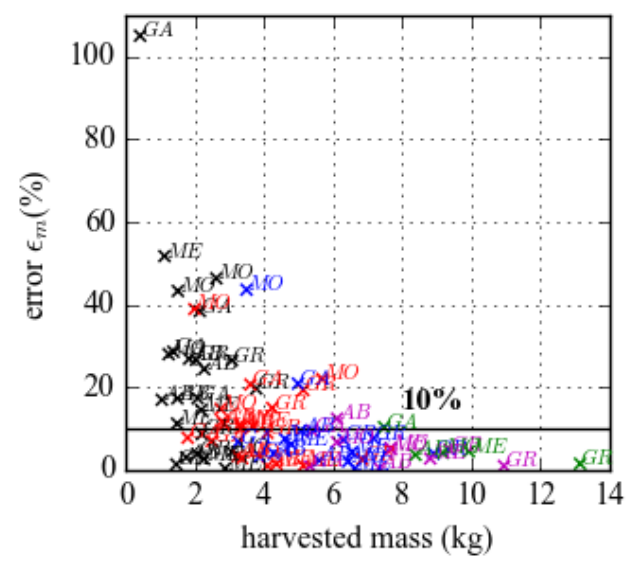

(b)

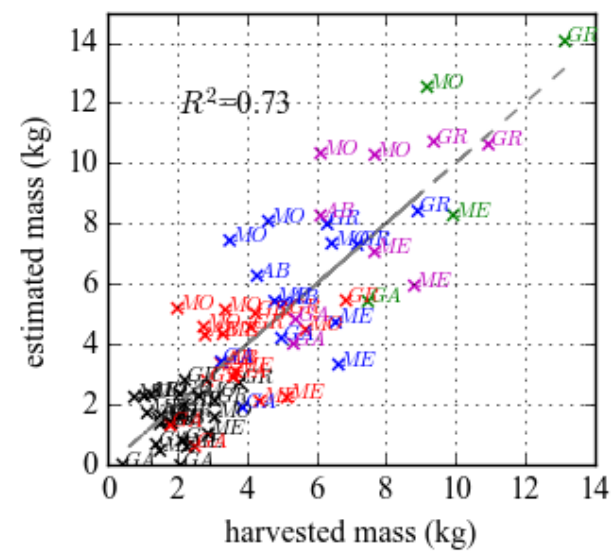

(c)

Fig. 9. (a) Estimated mass versus harvested mass of grapes derived from the estimator $E_{n}^{\text {Pol }}$ at $24 \mathrm{GHz}$. (b) estimation error $\varepsilon_{m}$ versus harvested mass. (c) Estimated mass versus harvested mass of grapes after harvesting (i.e., without grapes in the vine plant). 
The estimation error $\varepsilon_{\operatorname{lin}}$ of the linear model for $N$ combination of grape masses can be defined as follows:

$$
\varepsilon_{\text {lin }}=\sqrt{\frac{1}{N} \sum_{n=1}^{N}\left|m_{\text {lin }, n}-m_{\text {est }, n}\right|^{2}}
$$

where $m_{l i n, n}$ is the grape mass derived from the linear model, and $m_{e s t, n}$ denotes the estimated grape mass of the $n$-th vine plant. The estimation error $\varepsilon_{l i n}$ is of $0.50 \mathrm{~kg}$. Moreover, the mass estimation error $\varepsilon_{m, n}$ for the $n$-th vine plant can be defined by the following relationship:

$$
\varepsilon_{m, n}=\frac{\left|m_{\text {harv }, n}-m_{e s t, n}\right|}{m_{e s t, n}}
$$

where $m_{\text {harv,n }}$ denotes the harvested mass for this plant. As a consequence, the mass estimation error for the $N$ measured vine plants can be computed as follows:

$$
\varepsilon_{m}=\frac{\sum_{n=1}^{N}\left|m_{h a r v, n}-m_{e s t, n}\right|}{\sum_{n=1}^{N} m_{e s t, n}}
$$

The total harvested mass of grapes (including all varieties) is of $48.1 \mathrm{~kg}$ while the total estimated grape mass is of $48.6 \mathrm{~kg}$. It leads to a very low estimation error of yield $\left(\varepsilon_{m}=1.1 \%\right)$. This error is displayed in Figure 9(b) as a function of the harvested mass. It can be observed that the higher is the mass, the lower is the error. This experimental result may be interpreted as follows:

$i$. In practice, grape mass per vine plant is measured manually plant per plant, but some grapes are located at the vicinity of two vine plants. It generates error of the ground-truth measurements which is compensated by the combination of masses of consecutive vine plants;

ii. Side lobes of the radar transmitting antenna (around 18dB between the amplitude at the peak of the main lobe and the amplitude at the peak of the side lobes) interrogate vine plant on both sides of the main lobe direction. Consequently, the radar image may contain echoes from plants located on both sides of the plant illuminated by the radar main lobe. As a result, an estimation error of the yield may occur, but is compensated from the combination of grape masses of consecutive vine plants.

The proposed polarimetric analysis is also useful to assess the complexity of the vineyard environment. For example, the obtained positive value of $a_{V H}^{H H}(=+0.66)$ means that, compared with the $V H$ polarization configuration, the electromagnetic backscattering of regions containing grapes is higher in the $H H$ polarization configuration. At the opposite, the negative value of coefficient $a_{H V}^{H H}(=-0.44)$ indicates that the backscattering of regions without vine grapes is higher for the polarization configuration $H H$ than for the configuration $H V$.

To complete the yield estimation from the proposed polarimetric analysis, measurements of vine plants are performed after the harvesting, that is, without grapes in vine plants. In this case, the estimation of grape mass is expected to be zero. The mass is estimated using the coefficients $a_{q}^{p}$ reported in Table IV and is displayed in Figure 8(c) as a function of the harvested mass. It can be observed that the mass estimation is (unfortunately) not zero. It means that the yield is not estimated from the electromagnetic backscattering of grapes only, but also from the clutter (leaves, shoots, trunk ...). After the harvesting, when grapes are no more present in the scene, the clutter generates erroneous estimations of the yield. However, we note a degradation of the estimator linearity $\left(R^{2}=0.73\right)$, which means that $E_{n}^{P o l}$ is indeed an good estimator of the grape yield. It seems that this estimator does not detect grapes as isolated targets, but as targets "in a grapevine environment". At first glance, this could be problematic but leaves and shoots (which contribute to the measured EM backscattering) are related to the foliage density and the vine vigor of the grapevine. It has been demonstrated that these two vegetal indicators are strongly correlated to the grape yield [35] [36], and consequently, may not degrade the yield estimation. The estimation errors $\varepsilon_{l i n}$ and $\varepsilon_{m}$ provided by the estimator $E_{n}^{P o l}$ defined in eq.(4-a) are reported in Table $\mathrm{V}$ for various deviations $\delta t$ from the initial threshold $t_{\text {init }}$. For $\delta t$ ranging from $-4 d B$ to $+2 d B$, it can be observed that the mass estimation error $\varepsilon_{m}$ does not exceed 3.7\%. If required, this error could be reduced by re-computing $\delta_{\alpha}, \alpha_{R E F}^{p}$ and $\beta_{R E F}^{p}$ from the measurement of more vine plants. Table $\mathrm{V}$ reports also the estimation errors $\varepsilon_{l i n}$ and $\varepsilon_{m}$ provided by the estimator $E_{n}^{P o l}$ for the truncated elevation angle range $\Delta \theta=\left[\theta_{\text {Min }}, \theta_{\text {Max }}\right]$ of the beam-scanning. When the truncation $\Delta \theta$ is about few degrees, the estimation accuracy of the yield is not degraded. However, this is not the case when $\theta_{\text {Max }} \leq 26^{\circ}$ and $\theta_{\text {Min }} \geq 8^{\circ}$. Consequently, the estimator $E_{n}^{P o l}$ is accurate only for given range $\Delta \theta$ of elevation angle that comprises a given number of radar echoes with a proximal error $\theta_{\operatorname{Max}}$ of $\pm 2^{\circ}$ and $\theta_{\text {Min }}$ of $\pm 4^{\circ}$. If a larger or smaller $\Delta \theta$ is used, the number of radar echoes respectively increases or decreases, and the $a_{q}^{p}$ coefficients should be re-calculated. 
TABLE V

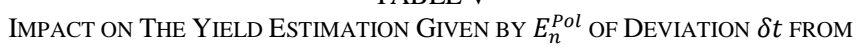
THE INITIAL THRESHOLD $t_{\text {init }}$

\begin{tabular}{cccccc}
\hline \hline$\delta t(\mathrm{~dB})$ & -4 & -2 & 0 & 2 & 4 \\
\hline$\varepsilon_{\text {lin }}(\mathrm{kg})^{\mathrm{a}}$ & 0.59 & 0.58 & 0.50 & 0.69 & 0.98 \\
$\varepsilon_{\mathrm{m}}(\%)^{\mathrm{b}}$ & 3.7 & 0.2 & 1.1 & 2.1 & 10.1 \\
$\mathrm{R}^{2}$ & 0.955 & 0.952 & 0.965 & 0.939 & 0.883 \\
\hline$\Delta \theta\left(^{\circ}\right)$ & {$\left[0^{\circ}, 30^{\circ}\right]$} & {$\left[0^{\circ}, 28^{\circ}\right]$} & {$\left[0^{\circ}, 26^{\circ}\right]$} & {$\left[0^{\circ}, 24^{\circ}\right]$} & {$\left[0^{\circ}, 22^{\circ}\right]$} \\
\hline$\varepsilon_{\text {lin }}(\mathrm{kg})^{\mathrm{a}}$ & 0.50 & 0.51 & 0.74 & 1.45 & 2.04 \\
$\varepsilon_{\mathrm{m}}(\%)^{\mathrm{b}}$ & 1.1 & 1.0 & 25.4 & 31.5 & 62.0 \\
$\mathrm{R}^{2}$ & 0.965 & 0.964 & 0.932 & 0.910 & 0.882 \\
\hline$\Delta \theta\left(^{\circ}\right)$ & {$\left[0^{\circ}, 30^{\circ}\right]$} & {$\left[2^{\circ}, 30^{\circ}\right]$} & {$\left[4^{\circ}, 30^{\circ}\right]$} & {$\left[6^{\circ}, 30^{\circ}\right]$} & {$\left[8^{\circ}, 30^{\circ}\right]$} \\
\hline$\varepsilon_{\text {lin }}(\mathrm{kg})^{\mathrm{a}}$ & 0.50 & 0.52 & 0.54 & 0.67 & 0.97 \\
$\varepsilon_{\mathrm{m}}(\%)^{\mathrm{b}}$ & 1.1 & 1.5 & 0.5 & 0.6 & 1.5 \\
$\mathrm{R}^{2}$ & 0.965 & 0.963 & 0.959 & 0.938 & 0.883 \\
\hline \hline
\end{tabular}

${ }^{a} \varepsilon_{\text {lin }}:$ mass estimation error from the linear model $\left(N_{0}=25\right.$ vine plants for $N=75$ combinations of grape masses), as defined in eq.(11).

${ }^{\mathrm{b}} \varepsilon_{\mathrm{m}}$ : mass estimation error $\left(N_{0}=25\right.$ vine plants for $N=75$ combinations of grape masses), as defined in eq.(12-b)

Although it provides encouraging results, the polarimetric analysis requires radar sensor with independent transmission and reception channels (Note that the receiving antenna has been alternatively rotated by $0^{\circ}$ and $90^{\circ}$ to receive both vertically and horizontally polarized field, since the $D K$-sR-1030e radar has only one transmitting channel). Moreover, the transmitting antenna must have a narrow beamwidth for a sufficient image angular resolution and consequently, may lead at $24 \mathrm{GHz}$ to large antenna dimensions.

\section{Yield ESTIMATION FROM RAdar IMAgES IN THE POLARIZATION CONFIGURATION VV}

In this section the grape vine yield is estimated from radar images obtained in the polarization configuration $p=\mathrm{VV}$ only and at three frequencies (24GHz, $77 \mathrm{GHz}$ and $122 \mathrm{GHz}$ ).

Let $E_{n}^{M a g}$ be the statistical estimator of grape mass of the $n$-th vine plant defined as follows:

$$
E_{n}^{M a g}=\sum_{q=\max , \text { mean }, \text { std }} a_{q} x_{n, q}^{V V}
$$

with

$$
x_{n, q}^{V V}=\frac{1}{s_{R E F}^{V V}} \sum_{k=1}^{K_{n}^{V V}} s_{k}^{V V}\left(\mathcal{C}_{k, n}^{V V}\right) e_{q}\left(\mathcal{C}_{k, n}^{V V}\right)
$$

where $e_{\text {max }}\left(\mathcal{C}_{k, n}^{V V}\right), e_{\text {mean }}\left(\mathcal{C}_{k, n}^{V V}\right)$ and $e_{s t d}\left(\mathcal{C}_{k, n}^{V V}\right)$ denote respectively the echo peak, echo mean value and standard deviation of radar echoes in the surface domain delimited by the $k$-th contour $\mathcal{C}_{k, n}^{V V}$ and in the polarization configuration $V V$. The computation of the reference domain $s_{R E F}^{V V}$ is detailed in Section III.A. The real coefficients $a_{q}$ in eq.(13-a) are derived from solving the following equation:

$$
Y^{V V}=A^{V V} X^{V V}
$$

where

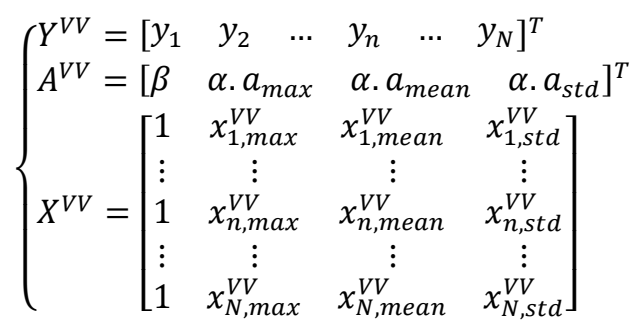

These coefficients are computed from the technique described in Section III.A. The characteristics and parameters of the estimator $E_{n}^{M a g}$ are reported in Table VI. The estimated mass of grapes obtained at $24 \mathrm{GHz}, 77 \mathrm{GHz}$ and $122 \mathrm{GHz}$, as well as estimation error 
$\varepsilon_{m}$ at these frequencies are displayed in Figure 10 as a function of the harvested mass (NB: because measurements at $122 \mathrm{GHz}$ were performed only for the three varieties $\mathrm{ME}$, GR and $\mathrm{AB}$, the yield estimation form $E_{n}^{\text {Mag }}$ at $24 \mathrm{GHz}$ and $77 \mathrm{GHz}$ is also given in this section only for these three varieties).

TABLE VI

YIELD ESTIMATION BASED ON RADAR ECHO MAGNITUdES IN POLARIZATION CONFIGURATION VV

\begin{tabular}{c|cc|cc}
\hline \hline Radar sensor & Characteristics & \multicolumn{2}{c}{ Parameters } \\
\hline & Total harvested mass $(\mathrm{kg})$ & 48.1 & $\alpha(\mathrm{g} / \mathrm{dB})$ & $3.4 \mathrm{E}-4$ \\
& Total estimated mass $(\mathrm{kg})$ & 56.7 & $\beta(\mathrm{g})$ & $3.5 \mathrm{E}-2$ \\
(24GHz) & $R^{2}$ & 0.79 & $a_{\text {max }}$ & -0.55 \\
DK-sR-1030e & ${\text { error } \varepsilon_{\text {lin }}(\mathrm{kg})^{\mathrm{a}}}^{\mathrm{a}}$ & 1.37 & $a_{\text {mean }}$ & 0.52 \\
& $\varepsilon_{\mathrm{m}}$ total $(\%)^{\mathrm{b}}$ & 17.8 & $a_{\text {std }}$ & 0.64 \\
\hline & Total harvested mass $(\mathrm{kg})$ & 48.1 & $\alpha(\mathrm{g} / \mathrm{dB})$ & $5.7 \mathrm{E}-6$ \\
& Total estimated mass $(\mathrm{kg})$ & 51.9 & $\beta(\mathrm{g})$ & $3.3 \mathrm{E}-3$ \\
$(77 \mathrm{GHz})$ & $R^{2}$ & 0.90 & $a_{\text {max }}$ & -0.67 \\
RBK_8 & error $\varepsilon_{\text {lin }}(\mathrm{kg})^{\mathrm{a}}$ & 0.91 & $a_{\text {mean }}$ & 0.61 \\
& $\varepsilon_{\mathrm{m}}$ total $(\%)^{\mathrm{b}}$ & 7.3 & $a_{\text {std }}$ & 0.40 \\
\hline & Total harvested mass $(\mathrm{kg})$ & 31.4 & $\alpha(\mathrm{g} / \mathrm{dB})$ & $2.7 \mathrm{E}-5$ \\
& Total estimated mass $(\mathrm{kg})$ & 31.1 & $\beta(\mathrm{g})$ & $2.9 \mathrm{E}-3$ \\
$(122 \mathrm{GHz})$ & $R^{2}$ & 0.97 & $a_{\text {max }}$ & -0.38 \\
EasyRadar & ${\text { error } \varepsilon_{\text {lin }}(\mathrm{kg})^{\mathrm{a}}}^{\mathrm{a}}$ & 0.47 & $a_{\text {mean }}$ & 0.39 \\
& $\varepsilon_{\mathrm{m}}$ total $(\%)^{\mathrm{b}}$ & 0.9 & $a_{\text {std }}$ & 0.83 \\
\hline \hline
\end{tabular}

${ }^{\mathrm{a}} \varepsilon_{\text {lin }}:$ mass estimation error from the linear model model $\left(N_{0}=15\right.$ or $N_{0}=25$ vine plants for respectively $N=45$ or $N=75$ combinations of grape masses), as defined in eq.(11).

${ }^{\mathrm{b}} \varepsilon_{\mathrm{m}}$ : mass estimation error ( $N_{0}=15$ or $N_{0}=25$ vine plants for respectively

$N=45$ or $N=75$ combinations of grape masses), as defined in eq.(12-b)
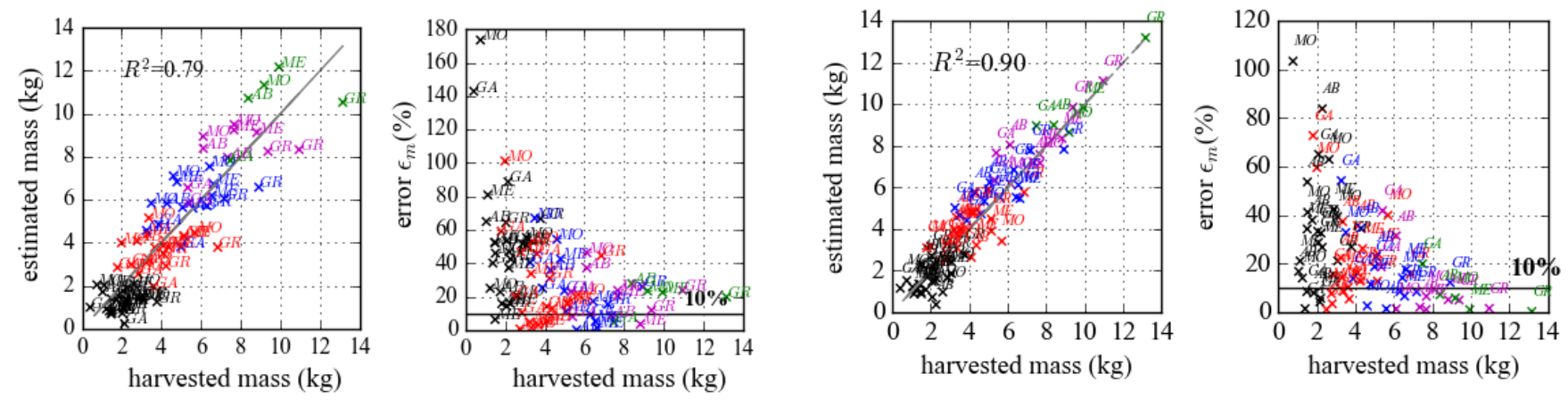

(a)

(b)
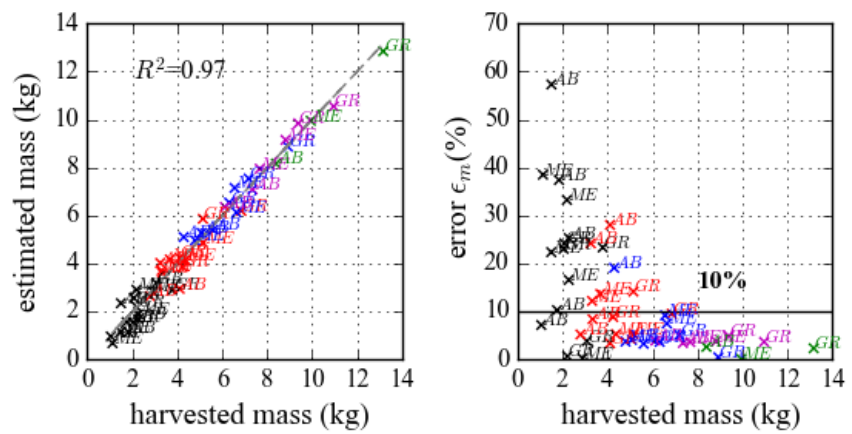

(c)

Fig. 10. Estimated mass (left) and estimation error $\varepsilon_{m}$ (right) versus harvested mass of grapes derived from the estimator $E_{n}^{\text {Mag }}$ at (a) $24 \mathrm{GHz}$, (b) $77 \mathrm{GHz}$ and (c) $122 \mathrm{GHz}$. 
At $24 \mathrm{GHz}$, the coefficient of determination $\left(R^{2}=0.79\right)$ deviates significantly from 1 . From Figure 10 (a) it can be observed that the error $\varepsilon_{m}$ does not tend towards $10 \%$ as the harvested mass increases. Moreover, the total harvested mass (including all varieties) is of $48.1 \mathrm{~kg}$ while the total estimated mass is of $56.7 \mathrm{~kg}$. As a result, it can be concluded that the estimation error $\left(\varepsilon_{m}=17.8 \%\right)$ is large when using the polarization configuration $V V$ at $24 \mathrm{GHz}$. No significant improvements are observed when only three varieties (ME, GR or AB) is considered.

At higher frequencies and for larger modulation bandwidth, better results are obtained from this specific polarization configuration. As it can be derived from Figure 10(b), when using the MIMO FM-CW radar operating at 77GHz (bandwidth $B$ of $3 \mathrm{GHz}$ ), the coefficient of determination $\left(R^{2}=0.90\right)$ is higher than one obtained at $24 \mathrm{GHz}$, and the estimation error is lower $\left(\varepsilon_{m}=7.3 \%\right)$. However, these results obtained at $77 \mathrm{GHz}$ from the polarization configuration $V V$ are not as good as those derived from the polarimetric analysis based on the estimator $E_{n}^{P o l}$ (see section III.B). Moreover, although the digital beamforming allows fast radar echo measurements, the angular resolution of the $R B K \_8$ radar is limited by the large beamwidth (51 ${ }^{\circ}$ in azimuth) of the transmitting antennas. Note that the coefficient of determination $R^{2}$ reaches 0.93 when only three varieties (ME, GR or AB) is considered with an estimation error $\varepsilon_{m}$ of $4.5 \%$.

The best mass estimation results are obtained when using the FM-CW radar operating at 122GHz. From Figure 10(c) it can be derived that the estimator $E_{n}^{\mathrm{Mag}}$ is linearly-dependent on the harvested mass $\left(\mathrm{R}^{2}=0.97\right)$ and the estimation error of grape mass is much lower than $10 \%\left(\varepsilon_{m}=0.9 \%\right)$. These excellent performances originate in the available larger modulation bandwidth $(B=6.8 \mathrm{GHz})$ leading to higher depth resolution, as well as a smaller wavelength that increases the interaction between grapes and incident EM field. For the sake of illustration, Figure 11 displays the estimated mass of grapes per contour before (i.e., with grapes) and after (i.e., without grape) the harvest. This mass is derived from the estimator $E_{n}^{M a g}$ at $122 \mathrm{GHz}$ and for five consecutive vine plants of Grenache. A clear difference can be observed on the number of contours that is clearly representative of a direct detection of fruit quantity.

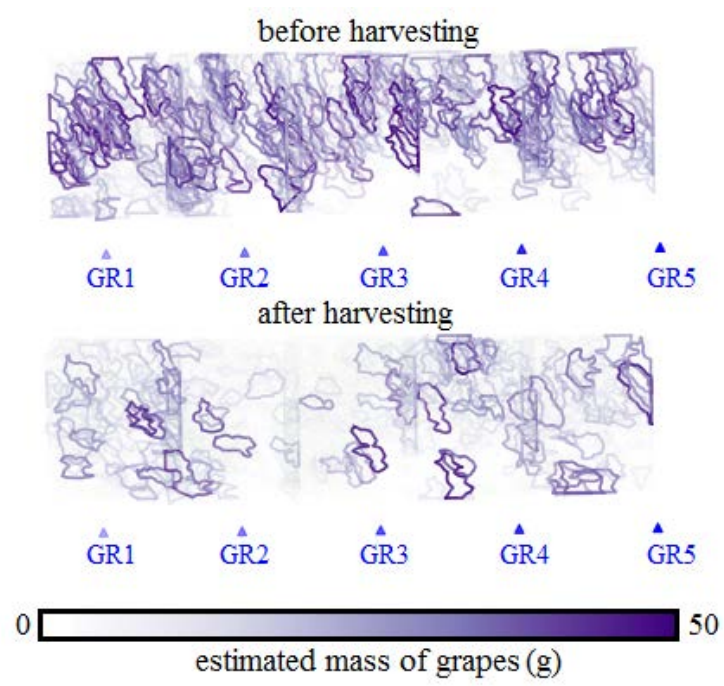

Fig. 11. Estimated mass of grapes per contour at $122 \mathrm{GHz}$ provided by estimator $E_{n}^{M a g}$ before and after the harvest of five vine plants of Grenache. Dark purple contours contain more grapes than lighter contours (threshold of 50g).

The sum $s_{\text {tot }}^{V V}$ of all surfaces that are delimited by the contours computed at $122 \mathrm{GHz}$ from the self-adaptive algorithm (see Section II.D) is calculated from eq.(5). The reference surface $s_{R E F}^{V V}$ defined by eq.(7-a) is then derived from eq.(7-b) with $\delta_{\alpha}=6.1 \mathrm{E}-2 \mathrm{~dB}{ }^{-1}$. The resulting estimation errors $\varepsilon_{\text {lin }}$ and $\varepsilon_{m}$ provided by the estimator $E_{n}^{M a g}$ are reported in Table VII for various deviations $\delta t$ from the initial threshold $t_{\text {init }}$. Compared with estimator $E_{n}^{\text {Pol }}$, the impact of deviation $\delta t$ on the yield estimation provided by $E_{n}^{M a g}$ is lower. In order to guarantee an estimation error lower than $5 \%, \delta t$ can be chosen such that $-2 d B<\delta t \leq 2 d B$. The computation of $E_{n}^{M a g}$ for different values of $\Delta \theta=\left[\theta_{\text {Min }}, \theta_{\text {Max }}\right]$ shows that more than $50 \%$ of the estimated mass of grapes is calculated for an elevation between $\theta_{\text {Min }}=10^{\circ}$ and $\theta_{\operatorname{Max}}=20^{\circ}$. Another $25 \%$ of the grape mass is found between $\theta_{\operatorname{Min}}=0^{\circ}$ and $\theta_{\text {Max }}=10^{\circ}$. Finally, the remaining $25 \%$ is estimated for an elevation angle between $\theta_{\operatorname{Min}}=20^{\circ}$ and $\theta_{\operatorname{Max}}=30^{\circ}$. 
TABLE VII

IMPACT ON THE YIELD ESTIMATION GIVEN BY $E_{n}^{M a g}$ OF DEVIATION $\delta t$ FROM THE INITIAL THRESHOLD $t_{\text {init }}$

\begin{tabular}{cccccc}
\hline \hline$\delta t(\mathrm{~dB})$ & -4 & -2 & 0 & 2 & 4 \\
\hline$\varepsilon_{\text {lin }}(\mathrm{kg})^{\mathrm{a}}$ & 0.70 & 0.57 & 0.47 & 0.54 & 0.64 \\
$\varepsilon_{\mathrm{m}}$ total $^{\mathrm{b}}(\%)$ & 7.3 & 5.4 & 0.9 & 1.5 & 2.9 \\
$\mathrm{R}^{2}$ & 0.948 & 0.964 & 0.972 & 0.965 & 0.953 \\
\hline$\Delta \theta\left(^{\circ}\right)$ & {$\left[0^{\circ}, 30^{\circ}\right]$} & {$\left[0^{\circ}, 28^{\circ}\right]$} & {$\left[0^{\circ}, 26^{\circ}\right]$} & {$\left[0^{\circ}, 24^{\circ}\right]$} & {$\left[0^{\circ}, 22^{\circ}\right]$} \\
\hline$\varepsilon_{\text {lin }}(\mathrm{kg})^{\mathrm{a}}$ & 0.47 & 0.47 & 0.53 & 0.72 & 1.18 \\
$\varepsilon_{\mathrm{m}}$ total $^{\mathrm{b}}(\%)$ & 0.9 & 1.3 & 4.7 & 10.8 & 21.3 \\
$\mathrm{R}^{2}$ & 0.972 & 0.972 & 0.968 & 0.962 & 0.926 \\
\hline$\Delta \theta\left(^{\circ}\right)$ & {$\left[0^{\circ}, 30^{\circ}\right]$} & {$\left[2^{\circ}, 30^{\circ}\right]$} & {$\left[4^{\circ}, 30^{\circ}\right]$} & {$\left[6^{\circ}, 30^{\circ}\right]$} & {$\left[8^{\circ}, 30^{\circ}\right]$} \\
\hline$\varepsilon_{\text {lin }}(\mathrm{kg})^{\mathrm{a}}$ & 0.47 & 0.49 & 0.52 & 0.71 & 1.02 \\
$\varepsilon_{\mathrm{m}}$ total $^{\mathrm{b}}(\%)$ & 0.9 & 2.9 & 6.0 & 12.5 & 21.4 \\
$\mathrm{R}^{2}$ & 0.972 & 0.971 & 0.972 & 0.969 & 0.969 \\
\hline \hline
\end{tabular}

${ }^{a} \varepsilon_{\text {lin }}:$ mass estimation error from the linear model ( $N_{0}=15$ vine plants for $N=45$ combinations of grape masses), as defined in eq.(11).

${ }^{\mathrm{b}} \varepsilon_{\mathrm{m}}$ : mass estimation error model ( $N_{0}=15$ vine plants for $N=45$ combinations

of grape masses), as defined in eq.(12-b)

\section{PERSPECTIVES}

The next step consists of embedding the proximal sensors on vehicles (quads, agricultural straddles or tractors ...) to perform the convenient grape yield estimation for entire vineyards. Such on-the-fly estimation will require the simultaneous control of measurement time of radar data, ground speed of the vehicle, estimation error of the grape mass and analyses of repeatability. Moreover, the reported work was focused on the yield estimation at the maturation stage of vine plants and for five grape varieties only. Future works will assess the yield estimation at earlier stages of the fruit growth, for different environmental conditions and for more varieties of grapes.

\section{CONCLUSION}

This paper has reported the contact-less estimation of vine grape yield from a three-dimensional radar imagery technique. Three ground-based frequency-modulated continuous-wave radars operating respectively at $24 \mathrm{GHz}, 77 \mathrm{GHz}$ and $122 \mathrm{GHz}$ have been used. Two statistical estimators of grape mass have been defined from the polarization and magnitude of radar echoes. Accurate estimation (within 1 per cent) has been obtained at 122GHz from the polarization configuration VV for three varieties of vine plants. Yield estimation with the 77GHz MIMO radar is also encouraging with an estimation error of the mass of $7.3 \%$ for five varieties of vine plants. It demonstrates the feasibility of accurate and contact-less estimation of vine grape yield from millimeterwave proximal radar sensors. Therefore this result must be accompanied and validated by numerous measurements in various environmental conditions on an integrated vehicle.

\section{ACKNOWLEDGMENTS}

The authors would like to thank the French Agency for Technological Research (ANRT) and Ovalie-Innovation subsidiary of Vivadour and Maisadour Cooperative Groups for financial support, and Eric Serrano and the staff of IFV Sud-Ouest (Institut Français de la Vigne et du Vin) for their expertise and the authorized access of the IFV Sud-Ouest vineyards.

\section{REFERENCES}

[1] R. G. V. Bramley and A. P. Proffitt, "Managing variability in viticultural production”, Aust. N. Z. Grapegrow. Winemak., no. 427, 1999, pp. 11-16, 1999.

[2] D. J. Mulla, "Twenty five years of remote sensing in precision agriculture: Key advances and remaining knowledge gaps”, Biosyst. Eng., vol. 114, no 4, pp. 358-371, Apr. 2013.

[3] R. Chamelat, E. Rosso, A. Choksuriwong, C. Rosenberger, H. Laurent, and P. Bro, “Grape Detection By Image Processing”, in IECON 2006 - 32nd Annual Conference on IEEE Industrial Electronics, 2006, pp. 3697-3702.

[4] S. Liu and M. Whitty, “Automatic grape bunch detection in vineyards with an SVM classifier”, J. Appl. Log., vol. 13, no 4, Part 3, pp. 643-653, Dec. 2015.

[5] R. Berenstein, O. B. Shahar, A. Shapiro, and Y. Edan, "Grape clusters and foliage detection algorithms for autonomous selective vineyard sprayer", Intell. Serv. Robot., vol. 3, no 4, p. 233-243, Oct. 2010.

[6] P. Škrabánek and P. Doležel, "Robust Grape Detector Based on SVMs and HOG Features”, Comput. Intel. Neurosci., vol. $2017,2017$.

[7] S. Nuske, S. Achar, T. Bates, S. Narasimhan, and S. Singh, "Yield estimation in vineyards by visual grape detection”, in 2011 IEEE/RSJ International Conference on Intelligent Robots and Systems, 2011, pp. 2352-2358.

[8] R. Roscher, K. Herzog, A. Kunkel, A. Kicherer, R. Töpfer, and W. Förstner, “Automated image analysis framework for high-throughput determination of grapevine berry sizes using conditional random fields”, Comput. Electron. Agric., vol. 100, pp. 148-158, Jan. 2014. 
[9] A. Aquino, B. Millan, M.-P. Diago, and J. Tardaguila, “Automated early yield prediction in vineyards from on-the-go image acquisition”, Comput. Electron. Agric., vol. 144, pp. 26-36, Jan. 2018.

[10] M. Gatti, A. Garavani, A. Vercesi, and S. Poni, "Ground-truthing of remotely sensed within-field variability in a cv. Barbera plot for improving vineyard management: Vigour mapping and vineyard management”, Austr Journ. Grape Wine Resear., vol. 23, pp.399-408, Oct 2017.

[11] M. Herrero-Huerta, D. González-Aguilera, P. Rodriguez-Gonzalvez, and D. Hernández-López, "Vineyard yield estimation by automatic 3D bunch modelling in field conditions”, Comput. Electron. Agric., vol. 110, pp. 17-26, Jan. 2015.

[12] N. Behroozi-Khazaei and M. R. Maleki, “A robust algorithm based on color features for grape cluster segmentation”, Comput. Electron. Agric., vol. 142, pp. 41-49, Nov. 2017.

[13] J. W. Rouse, R.H. Haas, J.A. Schell and D.W. Deering, "Monitoring vegetation systems in the Great Plains with ERTS”, 1974.

[14] L. Sun, F. Gao, M. C. Anderson, W. P. Justas, M. M. Alsina, L. Sanchez, B. Sams, L. McKee, W. Dulaney, W. A. White, J. G. Alfieri, J. H. Prueger, F. Melton, and K. Post, "Daily Mapping of 30 m LAI and NDVI for Grape Yield Prediction in California Vineyards", Remote Sens. $2017,9(4), 317$.

[15] M. Cunha, A. R. S. Marçal, and L. Silva, "Very early prediction of wine yield based on satellite data from VEGETATION", Int. J. Remote Sens., vol. 31, no 12, pp. 3125-3142, June 2010.

[16] A. Burini, A. Minchella, and D. Solimini, “SAR in agriculture: sensitivity of backscattering to grapes”, 2005 IEEE Intern. Geosc. Remote Sens. Symp. (IGARSS), vol. 3, pp. 1542-1545, 2005.

[17] J. D. Ballester-Berman, I. Garmendia-Lopez, J. M. Lopez-Sanchez, and V. J. Mangas-Martin, "Analysis of the polarimetric response of vineyards at Cband", Canadian Journal of Remote Sensing, Vol. 38, No. 3, pp. 223-239, 2012

[18] G. Schiavon, D. Solimini, and A. Burini, "Sensitivity of multi-temporal high resolution polarimetric C and L-band SAR to grapes in vineyards", 2007 IEEE Intern. Geosc. Remote Sens. Symp, pp. 3651-3654, July 2007.

[19] A. Burini, G. Schiavon, and D. Solimini, "Fusion of High Resolution Polarimetric SAR and Multi-Spectral Optical Data for Precision Viticulure”, 2008 IEEE Intern. Geosc. Remote Sens. Symp. (IGARSS), vol. 3, pp. III-1000-III-1003, July 2008.

[20] F. D. Frate, D. Latini, M. Picchiani, G. Schiavon, et C. Vittucci, "A neural network architecture combining VHR SAR and multispectral data for precision farming in viticulture”, 2014 IEEE Geosc. Remote Sens. Symp., pp. 1508-1511, July 2014.

[21] T. Véronèse, D. Henry, and H. Aubert, "System and method for estimating the yield of a cultivated plot”, WO patent $174248,2016$.

[22] B.A. Atayants, V.M. Davydochkin, V.V. Ezerskiy, V.S. Parshin, S. M. Smolskiy, "Precision FMCW short-range radar for industrial applications”, Artech House, 2014.

[23] "Products - IMST Radar", [Online] Available: www.radar-sensor.com/products/

[24] "INRAS Products - Radarbook", [Online] Available: www.inras.at/en/products/radarbook.html

[25] E. Ozturk, D. Genschow, U. Yodprasit, B. Yilmaz, D. Kissinger, W. Debski and W. Winkler, "Measuring Target Range and Velocity: Developments in Chip, Antenna, and Packaging Technologies for 60-GHz and 122-GHz Industrial Radars”, IEEE Microw. Mag., vol. 18, no 7, pp. 26-39, Nov. 2017.

[26] J. B. Hasted, "Liquid Water: Dielectric Properties”, Physics and Physical Chemistry of Water, Springer, Boston, MA,, pp. 255-309, 1972

[27] W. E. Lorensen and H. E. Cline, “Marching Cubes: A High Resolution 3D Surface Construction Algorithm”, Proc. 14th Annual Conf. Comput. Graph. Inter. Techn., New York, NY, USA, pp. 163-169, 1987.

[28] P. Ramachandran and G. Varoquaux, “ Mayavi: 3D Visualization of Scientific Data”, Comput. Sci. Eng., vol. 13, no 2, p. 40 -51, Mar. 2011.

[29] scikit-image: Image Processing SciKit (Toolbox for SciPy). [Online] Available: github.com/scikit-image

[30] Scipy library: Fundamental library for scientific computing. [Online] Available: github.com/scikit-image

[31] D. Henry, H. Aubert, T. Veronese, and E. Serrano, "Remote estimation of intra-parcel grape quantity from three-dimensional imagery technique using ground-based microwave FMCW radar”, IEEE Instrum. Meas. Mag., vol. 20, no 3, p. 20-24, June 2017.

[32] R. Penrose, “A generalized inverse for matrices”, Mathematical Proceedings of the Cambridge Philosophical Society, 51(3), 406-413.

[33] « NumPy» [Online] Available: www.numpy.org

[34] G. Strang, "Linear Algebra and Its Applications”, 2nd Ed., Orlando, FL, Academic Press, Inc., pp. 139-142, 1980

[35] E. Serrano, S. Roussel, L. Gontier, and T. Dufourcq, "Early Estimation of Vineyard Yield: Correlation Between the Volume of a Vitis vinifera Bunch During its Growth and its Weight at Harvest”, FRUITIC 05, Montpellier, France, 2005.

[36] R. E. Smart, J. K. Dick, I. M. Gravett, and B. M. Fisher, “Canopy Management to Improve Grape Yield and Wine Quality - Principles andPractices”, South Afr. J. Enol. Vitic., vol. 11, no 1, pp. 3-17, 1990. 